\title{
What do differences in case fatality ratios between children and adults tell us about COVID-19?
}

To the Editor:

CRISTIANi et al. [1] have raised interesting questions in their editorial discussing the differences in coronavirus disease 2019 (COVID-19) morbidity and mortality between children and adults. The authors proposed a number of possible reasons to explain why children suffer less severe illness, including age-related variation in angiotensin-converting enzyme (ACE) 2 receptor expression, trained immunity, and differences in lymphocyte and natural killer cell abundance. Whilst these hypotheses may be correct, we wish to challenge the notion that greater morbidity and mortality in adults is a remarkable feature of COVID-19. This is, in fact, the typical situation for most infections occurring in the absence of prior immunity.

The novel COVID-19 virus emerged into a previously unexposed and presumably fully susceptible population at the end of 2019, facilitating its rapid spread around the world. It has since been well documented that children with COVID-19 suffer a milder illness than adults, with better clinical outcomes overall. Age-specific case fatality ratios appear to increase continuously from close to $0 \%$ in children aged $<10$ years to $\sim 13 \%$ in adults aged $\geqslant 80$ years [2]. Globally, children suffer the greatest burden of most infectious diseases, particularly respiratory infections; hence, the low burden of COVID-19 in children has been viewed by many as surprising.

However, for most common infectious diseases, the relationships between age and disease severity are influenced by acquisition of immunity, and because immunity is dependent on exposure it therefore increases with age. When only susceptible individuals are considered, age-specific mortality rates are typically higher in adults than in children for most infectious diseases. This was observed for measles in historical first-contact island epidemics [3], and more recently for emerging infectious diseases including severe acute respiratory syndrome (SARS) [4], West Nile virus infection [5], and severe fever with thrombocytopenia syndrome (SFTS) [6]. Similar relationships are clear even for common infections causing their greatest burden in childhood, such as primary varicella infection [7] and Plasmodium falciparum malaria [8], when individuals without prior immunity are considered. We believe that the greater burden of COVID-19 in adults primarily reflects the fact that the whole population is susceptible, rather than an unusual association between severity and age.

Until we have better epidemiological data to be certain about denominators (numbers of infections in different age groups), it will be difficult to discern whether the relationship between age and case fatality ratio is monotonic or "J" shaped (with a higher case fatality ratio in the very youngest children compared with older children). However, comparisons between different age groups may tell us more about age-related host-pathogen interactions in general, than about the pathogenesis of COVID-19 specifically.

@ERSpublications

When individuals without prior immunity are considered, case fatality ratios are typically higher in adults than in children for most infectious diseases, with few exceptions https://bit.ly/2Wsi6iJ

Cite this article as: Ebmeier S, Cunnington AJ. What do differences in case fatality ratios between children and adults tell us about COVID-19? Eur Respir J 2020; 56: 2001601 [https://doi.org/10.1183/ 13993003.01601-2020].

Stefan Ebmeier $\odot$ and Aubrey J. Cunnington

Section of Paediatric Infectious Disease, St Mary's Campus Medical School Building, Imperial College London, London, UK.

Correspondence: Aubrey J. Cunnington, Section of Paediatric Infectious Disease, St Mary's Campus, Imperial College London, Medical School Building, Norfolk Place, London, W2 1PG, UK. E-mail: a.cunnington@imperial.ac.uk 
Conflict of interest: None declared.

\section{References}

1 Cristiani L, Mancino E, Matera L, et al. Will children reveal their secret? The coronavirus dilemma. Eur Respir J 2020; 55: 2000749.

2 Verity R, Okell LC, Dorigatti I, et al. Estimates of the severity of coronavirus disease 2019: a model-based analysis. Lancet Infect Dis 2020; 20: 669-677.

3 Shanks GD, Waller M, Briem H, et al. Age-specific measles mortality during the late 19th-early 20th centuries. Epidemiol Infect 2015; 143: 3434-3441.

4 Jia N, Feng D, Fang LQ, et al. Case fatality of SARS in mainland China and associated risk factors. Trop Med Int Health 2009; 14: Suppl. 1, 21-27.

5 Lindsey NP, Staples JE, Lehman JA, et al. Surveillance for human West Nile virus disease - United States, 1999 2008. MMWR Surveill Summ 2010; 59: 1-17.

$6 \mathrm{Li} \mathrm{H}, \mathrm{Lu} \mathrm{QB}$, Xing B, et al. Epidemiological and clinical features of laboratory-diagnosed severe fever with thrombocytopenia syndrome in China, 2011-17: a prospective observational study. Lancet Infect Dis 2018; 18: 1127-1137.

7 Brisson M, Edmunds WJ. Epidemiology of varicella-zoster virus in England and Wales. J Med Virol 2003; 70: Suppl. 1, S9-S14.

8 Checkley AM, Smith A, Smith V, et al. Risk factors for mortality from imported falciparum malaria in the United Kingdom over 20 years: an observational study. BMJ 2012; 344: e2116.

Copyright @eERS 2020.

This version is distributed under the terms of the Creative Commons Attribution Non-Commercial Licence 4.0.

From the authors:

We thank S. Ebmeier and A.J. Cunnington for their commentary on our editorial [1], providing another point of view on such a controversial topic. In their letter, S. Ebmeier and A.J. Cunnington assume that the greater burden of coronavirus disease 19 (COVID-19) in adults may be related to the absence in the population of prior immunity to severe acute respiratory syndrome coronavirus 2 (SARS-CoV-2), as occurred in fully susceptible populations during previous viral epidemics. In particular, SHANKs et al. [2] report that the measles mortality rate in a fully susceptible population during the 1846 measles epidemic was higher in adults and in children aged $<2$ years. However, nowadays, children younger than 5 years and adults older than 20 years are still more likely to suffer from measles complications, despite not being fully susceptible [3]. Moreover, STREBEL et al. [4] reported that the case fatality ratio is still high in children aged $<1$ year, lower in children aged 1-9 years, and then rises again in teenagers and adults. The reported data suggest that greater morbidity and mortality in adults is not a unique feature of first-contact measles epidemics.

As regards West Nile virus infection [5], severe fever with thrombocytopenia syndrome [6] and Plasmodium falciparum malaria [7], several factors such as pathogen features, transmission dynamics and population characteristics could be potential confounders; therefore, we think that these diseases may not be comparable to COVID-19. Moreover, Lindsey et al. [5] and Li et al. [6] described higher mortality rates in adults, but data were collected over several years and we are not sure that the populations can be considered fully susceptible over time.

Furthermore, the SARS-CoV-2 viral genome is $75-80 \%$ identical to the SARS-CoV virus that caused a global pandemic in 2002-2003 [8]. Human coronavirus infections are very common worldwide [9-11]. Recently, GRIFONI et al. [12] analysed adaptive immunity to SARS-CoV-2 and detected SARS-CoV-2-reactive $\mathrm{CD}^{+}{ }^{+} \mathrm{T}$-cells in $\sim 40-60 \%$ of unexposed individuals, suggesting a cross-reactive T-cell recognition between circulating "common cold" coronaviruses and SARS-CoV-2. In view of these overall considerations, we can speculate that SARS-CoV-2 infection may not have spread in a fully susceptible population. This hypothesis may be also confirmed by a previous study by FEDSON [13], which reported that the different age-related mortality during the 1918 influenza pandemic could be related to

@ERSpublications

Other reasons, rather than absence of prior immunity, could play a crucial role in the coronavirus dilemma that surrounds children https://bit.ly/36BzTaD

Cite this article as: Midulla F, Cristiani L, Mancino E. What do differences in case fatality ratios between children and adults tell us about COVID-19? Eur Respir J 2020; 56: 2001852 [https://doi.org/10.1183/ 13993003.01852-2020]. 
previous exposures to the H1N1-like viruses, suggesting a fundamental role of "antigenic imprinting" on individual response.

In conclusion, we are more likely to consider that other reasons, rather than absence of prior immunity, could play a crucial role in the dilemma regarding children and the coronavirus.

Fabio Midulla, Luca Cristiani and Enrica Mancino

Dept of Maternal Science, Paediatric Emergency Service, Sapienza University of Rome, Rome, Italy.

Correspondence: Fabio Midulla, Dept of Maternal Science, Paediatric Emergency Service, Sapienza University of Rome, Viale Policlnico 321, 00161, Rome, Italy. E-mail: midulla@uniroma1.it

Received: 18 May 2020 | Accepted: 21 May 2020

Conflict of interest: None declared.

\section{References}

1 Cristiani L, Mancino E, Matera L, et al. Will children reveal their secret? The coronavirus dilemma. Eur Respir J 2020; 55: 2000749

2 Shanks GD, Waller M, Briem H, et al. Age-specific measles mortality during the late 19th-early 20th centuries. Epidemiol Infect 2015; 143: 3434-3441.

3 National Center for Immunization and Respiratory Diseases, Division of Viral Diseases. Complications of Measles. Centers for Disease Control and Prevention. www.cdc.gov/measles/symptoms/complications.html Date last updated: 13 June 2019.

4 Strebel PM, Papania MJ, Gastañaduy PA, et al. Measles vaccines. In: Plotkin SA, Orenstein WA, Offit PA, et al., eds. Plotkin's Vaccines. 7th Edn. Philadelphia, Elsevier, 2018; pp. 579-618.

5 Lindsey NP, Staples JE, Lehman JA, et al. Surveillance for human West Nile virus disease - United States, 19992008. MMWR Surveill Summ 2010; 59: 1-17.

6 Li H, Lu QB, Xing B, et al. Epidemiological and clinical features of laboratory-diagnosed severe fever with thrombocytopenia syndrome in China, 2011-17: a prospective observational study. Lancet Infect Dis 2018; 18: $1127-1137$.

7 Checkley AM, Smith A, Smith V, et al. Risk factors for mortality from imported falciparum malaria in the United Kingdom over 20 years: an observational study. BMJ 2012; 344: e2116.

8 Zhou P, Yang XL, Wang XG, et al. A pneumonia outbreak associated with a new coronavirus of probable bat origin. Nature 2020; 579: 270-273.

9 Varghese L, Zachariah P, Vargas C, et al. Epidemiology and clinical features of human coronaviruses in the pediatric population. J Pediatric Infect Dis Soc 2018; 7: 151-158.

10 Gorse GJ, Patel GB, Vitale JN, et al. Prevalence of antibodies to four human coronaviruses is lower in nasal secretions than in serum. Clin Vaccine Immunol 2010; 17: 1875-1880.

11 Mancino E, Cristiani L, Pierangeli A, et al. A single centre study of viral community-acquired pneumonia in children: no evidence of SARS-CoV-2 from October 2019 to March 2020. J Clin Virol 2020; 128: 104385.

12 Grifoni A, Weiskopf D, Ramirez SI, et al. Targets of T cell responses to SARS-CoV-2 coronavirus in humans with COVID-19 disease and unexposed individuals. Cell 2020; in press [https://doi.org/10.1016/j.cell.2020.05.015].

13 Fedson DS. Influenza, evolution, and the next pandemic. Evol Med Public Health 2018; 2018: 260-269. 